\title{
A Segurança Comunitária e a Pandemia de COVID-19
}

\author{
Eduardo Pereira Correia * \\ Ricardo Claro ${ }^{\star *}$ \\ * Instituto Superior de Ciências Policiais e Segurança Interna, Portugal; eduardopereiracorreia@gmail.com \\ ** NOVA School of Law - Universidade Nova de Lisboa, Portugal; rbclaro@psp.pt
}

\section{Resumo}

Este artigo analisa o paradigma da segurança comunitária à luz da atual crise pandémica provocada pela COVID-19. Em plena evolução, a análise apresentada tem em consideração as atuais necessidades de segurança e de proteção civil, nomeadamente as vertentes securitárias da segurança comunitária. Através do desenvolvimento de estratégias que envolvem as forças e serviços de segurança, a comunidade e os cidadãos, os autores demonstram a importância prática da municipalização securitária através das polícias administrativas locais, evoluindo para uma importante regionalização da segurança. De igual forma são observadas estratégias de policiamento comunitário e de proximidade de acordo com as políticas públicas de segurança que apontam para uma maior consciência política na problematização securitária.

Palavras-chave: COVID-19; pandemia; polícia; segurança comunitária; políticas públicas

\begin{abstract}
This article analyses the community safety paradigm in the light of the current pandemic crisis caused by COVID-19. In full evolution, the analysis presented considers the current security and civil protection needs, in particular the security aspects of community security. Through the development of strategies involving security forces and services, the community and citizens, the authors demonstrate the practical importance of security municipalisation through local administrative police, evolving into an important regionalization of security. Similarly, community policing and proximity strategies are observed in accordance with public security policies that point to greater political awareness in security problematization.
\end{abstract}

Keywords: COVID-19; pandemic; police; community security; public policy 


\section{Introdução}

A segurança assume atualmente um papel indispensável na edificação de políticas públicas estatais, sobretudo tendo em conta a relação direta entre o direito à segurança e o livre exercício dos demais direitos, liberdades e garantias. De facto, a interdependência funcional entre o direito à liberdade e o direito à segurança ${ }^{[1]}$ conduz-nos a incluir a segurança como um direito e garantia constitucional para o livre exercício dos restantes direitos e para o normal funcionamento de um Estado de direito democrático.

Considerando as atuais ameaças e riscos na cena internacional, a segurança assume-se como uma temática presente e primordial para a comunidade internacional, para os Estados e para a própria sociedade. Ainda assim, a constitucionalização da segurança implica também considerar a promoção da segurança como uma tarefa fundamental do Estado (Valente, 2013, p. 26), a par da salvaguarda do princípio da legalidade democrática. Porém, se outrora a defesa do Estado, a garantia da independência soberana e a proteção da integridade territorial definiam a função securitária estatal, presentemente a referência à missão securitária, engloba diferentes problemáticas que em conjunto colocam em causa a segurança e complexificam a missão das entidades que a garantem.

Neste sentido, entenda-se que nas últimas décadas o conceito de segurança alargou-se, englobando diversificados assuntos que não eram considerados como problemas de segurança primários. Esta mudança direciona e orienta a atividade do Estado para os novos desafios da sociedade e para diversos campos de atuação (Correia, 2018, p. 8). Assistiu-se à densificação e expansão do conceito de segurança, aglomerando diversas conceções, como a segurança humana, a segurança política, a segurança sanitária, a segurança ambiental e a segurança escolar.

De acordo com esta perspetiva, conceitos como a segurança interna e externa e a defesa nacional, por si só, não são suficientes para definir uma conceção ampla da segurança, emergindo um conceito macro e abrangente de segurança nacional. Estes são critérios objetivados numa política macro de Segurança Nacional e que consistem em aumentar a segurança das instituições sociais, económicas e políticas do país (Huntington, 1985). Por outro lado, atente-se na importância relativa ao conjunto de estratégias e de ações necessárias para atingir ou assegurar o estado de Segurança Nacional, enquanto garantia da sobrevivência da nação em paz e liberdade (Correia, 2020, pp. 267-268). Assim, aquando da referência a segurança nacional há que considerar uma visão integrada dentro de quatro pilares: a defesa nacional e as forças armadas; a segurança interna e as forças de segurança; a segurança do estado e os serviços de informações; e a segurança comunitária e a proteção civil (Gouveia, 2018, p. 367). Deste modo, objetiva-se, de forma ampla, abordar todas as problemáticas e

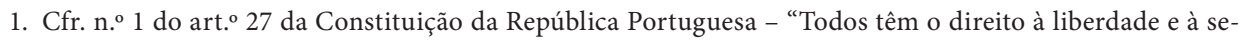
gurança". 
acontecimentos que influenciam a segurança da comunidade internacional, do Estado e da sociedade.

Neste quadro securitário, importa evidenciar a crescente influência das problemáticas ambientais, sanitárias e de proteção civil e socorro, dado que, em muitas situações de catástrofe natural, estão criadas condições ideais para a prática de atividades criminosas (Amaro, 2020, p. 8) e, por conseguinte, para um aumento do sentimento de insegurança. Desta forma, compreende-se não só a utilidade da colaboração entre as vertentes da segurança e da proteção civil, como também o necessário desenvolvimento das atribuições e competências das forças e serviços de segurança, das polícias municipais e das forças armadas no âmbito de proteção civil, emergência e socorro. Se o monopólio do uso da força por parte do Estado, como único garante da segurança, encontra-se em crise (Claro, 2018, p. 18), urge uma elaboração e reestruturação de políticas públicas de segurança que considerem outras vertentes como a proteção civil ou o socorro, por forma a abranger diversas problemáticas que, nesta pandemia, influenciam a segurança do Estado e dos cidadãos.

Tendo em conta a complexidade, difusão e constante mutação de ameaças e de riscos, existe uma cada vez maior interdependência entre o sistema de segurança interna, o sistema de proteção civil e o sistema de defesa nacional. Na atualidade, desafios securitários como a ocorrência de desastres ambientais, cheias, pandemias e incêndios maciços exigem uma resposta integrada e concertada das instituições de proteção civil, emergência e socorro, bem como das forças e serviços de segurança, e em certos casos das forças armadas, por forma a salvaguardar da segurança nacional.

Em consequência da pandemia provocada pelo vírus SARS-CoV2 e pela doença COVID-19 assiste-se a uma intensa e imprescindível atividade das instituições nacionais de proteção civil, socorro e emergência. De facto, através do serviço nacional de saúde, das entidades de emergência médica e de assistência social e dos serviços de proteção civil, diversas tarefas de auxílio são prosseguidas, procurando salvaguardar a resposta estatal e local face às necessidades pandémicas. Porém, não se pode relegar para segundo plano a atividade securitária quotidiana prosseguida pelas forças e serviços de segurança, pelas polícias municipais e pelas forças armadas. Estas entidades securitárias apoiam os serviços de proteção civil na prossecução da sua atividade, através de ações de auxílio e socorro e da fiscalização da implementação das medidas impostas para contenção da pandemia. Com efeito, estas instituições surgem como agentes de proteção civil e de saúde pública primários, a par da contínua prossecução das suas atribuições e competências específicas no âmbito da atividade de segurança interna.

\section{Segurança Comunitária: Uma Presença Nacional}

Tendo em consideração as atuais necessidades de segurança e de proteção civil, uma das vertentes securitárias que tem sido amplamente materializada é a segurança comunitária, através do desenvolvimento de estratégias que envolvem as forças e serviços de segurança, a comunidade e os cidadãos. Com base em modelos de respon- 
sabilidade partilhada, esta estratégia dota as autarquias locais de poderes de polícia de natureza administrativa e estabelece diretrizes policiais de proximidade com a sociedade civil.

Mediante a criação de polícias municipais e a estruturação de programas de policiamento de proximidade, a segurança comunitária assume uma presença capital na agenda securitária. Nesta perspetiva, constate-se que não só aproxima autarquias, comunidades locais e cidadãos das estruturas de segurança, envolvendo-os na produção e na garantia da segurança, como também permite compreender as problemáticas locais. Desta forma, importa clarificar, de modo sucinto, a materialização destas estratégias de segurança.

A criação das polícias municipais surgiu com o objetivo fundamental de cooperar com a missão de garantir a tranquilidade pública e a proteção de pessoas e bens, encontrando-se prevista no preceito constitucional ${ }^{[2]}$. Nesta senda, e conforme definido na lei-quadro das Polícias Municipais, as polícias municipais são serviços municipais com poderes de polícia administrativa, sendo a sua atribuição primordial a fiscalização do cumprimento das normas autárquicas ${ }^{[3]}$. A municipalização securitária tende a evidenciar-se como uma realidade crescente através da atuação das polícias administrativas locais que cooperam e competem com as forças de segurança territorialmente competentes e com o poder local. De igual modo, os polícias municipais revelam-se enquanto agentes de proteção civil, tendo em consideração a relevante tarefa colaborativa com as entidades de proteção e socorro autárquicas, bem como a importância do papel coordenador do município neste âmbito.

As diferentes autarquias tendem a criar a sua polícia municipal, o que representa uma mais-valia para a segurança local, através da vigilância e fiscalização de estabelecimentos, da vertente rodoviária ou tão somente da visibilidade policial preventiva quotidiana. Com a crescente constituição e organização de corpos de polícia municipais, assistimos a uma regionalização da segurança, ainda que parcial, uma vez que apenas prosseguem competências administrativas. As polícias municipais atuam como parceiros das forças e serviços de segurança nacionais através da prossecução de determinadas medidas de polícia.

No que diz respeito aos programas de policiamento de proximidade, os mesmos caracterizam-se pelo estabelecimento de um conjunto de medidas que pretendem aproximar a comunidade das polícias, apostando numa relação entre as forças de segurança e os cidadãos. Com efeito, é necessário intervir, de forma mais presente, junto dos grupos mais vulneráveis, com o objetivo de prevenir a delinquência - em especial, a juvenil - e obter a informação necessária para a reprimir. De seguida, é necessário que se adeque o policiamento para a prevenção, dando continuidade ao policiamento comunitário.

2. Cfr. n..$^{\circ}$ do art. ${ }^{\circ} 237$ da Constituição da República Portuguesa.

3. Cfr. n. ${ }^{\circ} 1$ do art. $^{\circ} 1$ e n. ${ }^{\circ} 1$ do art. $^{\circ} 2$ da Lei da Polícia Municipal, aprovada pela Lei n. ${ }^{\circ} 19 / 2004$, de 20 de maio, e alterada pela Lei n. ${ }^{\circ}$ 50/2019, de 24 de julho. 
A criação destes programas assenta na adoção de novos modelos de policiamento, nos quais se estabelecem parcerias com as comunidades locais e os cidadãos, envolvendo-os na produção de segurança (Gouveia, 2018, p. 106), permitindo a prossecução de políticas de sensibilização, bem como desenvolvendo instrumentos de prevenção securitária. Assim, a prevenção resulta da informação, da sensibilização e, por conseguinte, da presença policial assídua na comunidade local, objetivando diminuir os índices de criminalidade e de incumprimento das normas definidas.

Presentemente, o Modelo Integrado de Policiamento de Proximidade (MIPP) da Polícia de Segurança Pública (PSP) e os Programas Especiais de Policiamento de Proximidade (PEPP) da Guarda Nacional Republicana (GNR) têm-se demonstrado essenciais na proximidade necessária para o acompanhamento pandémico, conferindo uma perspetiva mais global e concertada da ação policial. Com o estabelecimento destas estruturas, a PSP e a GNR desenvolvem ações específicas no âmbito escolar, no contexto do comércio local, junto da população mais idosa, de vítimas de violência doméstica, bem como de vítimas de crimes. Através de formação e afetação específica de polícias e militares nestas temáticas, as forças de segurança pretendem uma atuação mais próxima, mais adequada e, sobretudo, mais presente, junto da comunidade mais sensível.

Desta forma, destaque-se que esta maior proximidade das forças de segurança com a comunidade reflete uma maior preocupação e intervenção política, por forma a compreender as problemáticas identitárias locais e apresentar uma resposta imediata aos problemas da comunidade. É neste sentido que estamos perante políticas públicas de segurança que surgem na necessidade de criar uma maior consciência política na problematização securitária.

Os modelos de responsabilidade securitária partilhada assumem-se, de facto, como uma tendência crescente e, cada vez mais, presente. No entanto, importa referir que a adoção de estratégias de segurança comunitária, "[...] nunca deve constituir uma desculpa para libertar o Estado de responsabilidades nesta área de soberania ou pôr em causa a sua unidade e a sua autoridade" (Pereira, 2017, p. 241).

Com efeito, o princípio de responsabilidade partilhada não deve minimizar o papel central e regulador do Estado, mas sim criar mecanismos de cooperação com diversos atores, desde as forças de segurança às autarquias e aos cidadãos, privilegiando a prevenção criminal e a manutenção da tranquilidade pública enquanto verdadeiras estratégias promotoras de segurança pública. Compreendendo a emergência de novos atores securitários e de novas políticas públicas de segurança, cabe-nos criar e reestruturar diversas estratégias que permitam desenvolver parcerias, adequando o quotidiano da missão securitária.

\section{As Polícias Municipais, o Policiamento de Proximidade e a Pandemia}

Em consequência da pandemia provocada pelo novo coronavírus SARS-CoV2 e pela doença COVID-19, verifica-se a necessária prossecução das missões de proteção civil, socorro e segurança, através da atuação de diferentes entidades, públicas ou pri- 
vadas, internacionais, nacionais ou locais. Considerando todos os efeitos nefastos na sociedade, importa prevenir a sua disseminação e a intensificação de determinadas problemáticas - sanitárias, económicas e securitárias - emergindo a necessária atuação coordenada de demais entidades como as forças e os serviços de segurança e as polícias municipais.

Em Portugal, no seguimento da declaração do estado de emergência, o livre exercício de diversos direitos foi suspenso ou limitado ${ }^{[4]}$, entre os quais: o direito de deslocação, o direito à propriedade e iniciativa privada, o direito de reunião e manifestação, o direito de resistência, o direito à liberdade de culto (coletivo) e o direito à circulação internacional. De modo semelhante, e apesar da diminuição das restrições e do início do processo de desconfinamento, em consequência da declaração da situação de calamidade, de contingência e de alerta, certos direitos continuam restringidos, como é exemplo o direito de deslocação dos doentes com COVID-19 e dos infetados com SARS-Cov2. Desta forma, importa destacar que o cumprimento das restrições impostas pelo Governo constitui não só um dever moral e ético de todos, como também um dever jurídico legalmente enquadrado por um quadro sancionatório criminal e contraordenacional. Assim, torna-se fundamental a fiscalização do cumprimento das medidas impostas, sensibilizando, prevenindo e reprimindo a conduta dos cidadãos que não cumpram as normas vigentes em cada momento.

Desde o início da implementação de medidas e de restrições de mitigação e contenção à propagação do novo coronavírus, é da competência das forças e serviços de segurança e das polícias municipais a fiscalização da implementação e do cumprimento de deveres e das obrigações impostas. Por um lado, cumpre a estas entidades, a sensibilização, o aconselhamento e a recomendação para a observância dos deveres legislados e, por outro lado, a emanação de ordens legítimas tais como o encerramento de estabelecimentos, a cessação das atividades suspensas e a cominação e participação do crime de desobediência, nos casos de incumprimento reiterado.

Com base em políticas públicas de segurança já edificadas, a utilização de estratégias de responsabilidade partilhada tem-se revelado fundamental nesta fase pandémica, em particular na informação e sensibilização junto da comunidade. No entanto, acresce que a fiscalização de medidas e restrições de contenção pandémica constitui um novo quotidiano securitário, a par da manutenção da ordem e da tranquilidade pública. Através da atuação das polícias municipais e da readaptação dos modelos especiais de policiamento de proximidade das forças de segurança, a segurança comunitária constitui-se como uma mais-valia na atual pandemia, não só no contexto fiscalizador, como no âmbito preventivo e sensibilizador junto dos cidadãos mais vulneráveis e da comunidade local.

4. Sobre a suspensão parcial do exercício de direitos vide o art. ${ }^{\circ} 4$ do Decreto do Presidente da República n. ${ }^{\circ}$ 14-A/2020, de 18 de março; o art. ${ }^{\circ} 4$ do Decreto do Presidente da República n. ${ }^{\circ}$ 17-A/2020, de 2 de abril; e o art. ${ }^{\circ} 4$ do Decreto do Presidente da República n. ${ }^{\circ} 20$-A/2020, de 17 de abril. 
No âmbito municipal, sendo os presidentes de câmara os responsáveis pelas ações de prevenção, socorro e assistência ${ }^{[5]}$ à comunidade, os mesmos adequam as funções e atribuições das polícias municipais, dotando-as de novas competências que permitam prosseguir e coadjuvar as missões de proteção civil. Note-se que nos contextos de estado de emergência, de situação de calamidade pública, de situação de contingência e de situação de alerta, as polícias municipais integram os serviços municipais de proteção civil ${ }^{[6]}$. Neste sentido, apesar da função primordial de polícia administrativa, as polícias municipais, como instrumento securitário local e serviço de proteção civil, desenvolvem ações específicas de visibilidade preventiva, de sensibilização e de apoio às entidades de proteção civil e às forças de segurança.

Através dos polícias afetos aos modelos de policiamento de proximidade, as forças de segurança adequam as suas estratégias e desenvolvem um policiamento mais próximo, objetivando sensibilizar a população para os riscos sanitários e também securitários, desta pandemia. A proximidade comunitária permitiu que a prevenção e sensibilização se tornasse mais simplificada, emergindo uma clara vantagem da reestruturação destas estratégias securitárias.

Assim, durante esta fase pandémica, as polícias, a par das suas atribuições e competências, desenvolvem diversas atividades específicas, entre as quais se assinalam: as operações de fiscalização aos estabelecimentos comerciais para verificação do seu encerramento ou do cumprimento das limitações impostas à sua atividade; as operações de fiscalização rodoviária, para apuramento dos motivos de circulação na via pública; as sessões de esclarecimentos prestadas aos estabelecimentos de ensino e ao comércio local; a assistência permanente aos idosos em risco; o acompanhamento contínuo às vítimas de violência doméstica; a limitação de acessos e dispersão de aglomerados populacionais; a fiscalização de consumo de bebidas alcoólicas na via pública; e a vigilância ativa de pessoas infetadas com SARS-CoV2 e doentes com COVID-19, para verificação do cumprimento do confinamento obrigatório.

Pelo exposto, importa referir que a prossecução destas atividades não se assumiu, nem assume, como uma tarefa simples, sobretudo devido à resistência da sociedade civil no cumprimento das restrições e das medidas impostas, e, por outro lado, da necessária adaptabilidade da atividade policial perante as emergentes alterações legislativas. Com efeito, destaque-se que o quadro sancionatório se alterou amiúde e de forma distinta no conjunto nacional, o que obrigou a uma contínua formação policial permitindo realizar a prevenção, sensibilização e repressão da comunidade.

Se no início da fase pandémica, as sanções assumiam um cariz exclusivamente criminal, através da cominação e participação do crime de desobediência, na fase de desconfinamento passaram a ter também uma vertente contraordenacional. Em primeiro lugar, este facto deveu-se à diminuição da restrição do livre exercício de

5. Cfr. n. ${ }^{\circ} 1$ do art. $^{\circ} 35$ da Lei de Bases de Proteção Civil, aprovada pela Lei n. ${ }^{\circ}$ 27/2006, de 3 de julho, e que contém a alteração mais recente introduzida pela Lei n. ${ }^{\circ}$ 80/2015, de 3 de agosto.

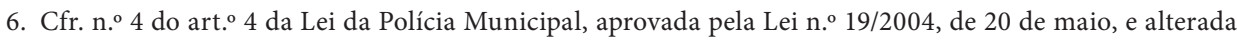
pela Lei n. ${ }^{\circ}$ 50/2019 de 24 de julho. 
direitos fundamentais e, em segundo, à perceção de um bom nível de acatamento por parte dos cidadãos. Contudo, importa sinalizar que, se por um lado mais situações estão a ser sancionadas no âmbito contraordenacional, por outro, as sanções criminais permanecem apenas tendo o seu lugar em situações mais específicas. Destaque-se que o incumprimento de determinados deveres impostos, constitui contraordenação, cumprindo a sua fiscalização e sancionamento à GNR, à PSP, à Polícia Marítima, à Autoridade de Segurança Alimentar e Económica (ASAE) e às polícias municipais.

Contudo, é expetável que em futuras e repetidas vagas pandémicas, o acatamento por parte dos cidadãos de medidas restritivas da liberdade, se torne cada vez menor e mais árduo. Tal poderá dever-se à não aquiescência de confinamento obrigatório por cansaço de repetidos estados de exceção, mas também com recurso a argumentos libertários, teorias conspirativas ou cidadãos oponentes à vacinação ${ }^{[7]}$.

Em suma, a sensibilização da comunidade civil e a fiscalização dos deveres, das restrições e das condicionantes impostas assumem-se como tarefas árduas e desafiantes para as forças e serviços de segurança. Neste sentido, a adaptação das estratégias de segurança comunitária no contexto pandémica evidencia-se como vantajosa, expondo a necessária readaptação das diretrizes e estratégias securitárias. Ainda que dotadas de um quadro repressivo contraordenacional e criminal, as forças e serviços de segurança prosseguem com atividades de sensibilização e prevenção junto da comunidade. Desta forma, objetiva-se prevenir o descontrolo da disseminação viral o que colocaria em causa a segurança da vida humana e as demais instituições de proteção civil, socorro e emergência médica.

\section{Conclusão}

Os modelos de segurança comunitária assumem-se como uma estratégia de valor acrescentado, resultando de um longo processo formativo de políticas públicas de segurança. A constituição de serviços de segurança locais e a aproximação da comunidade civil às estruturas securitárias têm sidos os métodos mais aplicados, demonstrando benefícios na prevenção e repressão criminal, nomeadamente ao nível dos índices da delinquência juvenil.

No contexto de estado de emergência, de situação de calamidade, de contingência e de alerta, os polícias afetos aos programas de policiamento de proximidade e as polícias municipais, além de prosseguirem com as suas missões específicas, fiscalizam o cumprimento das restrições legalmente impostas e apoiam os serviços de prote-

7. A título de exemplo, vejam-se os inúmeros protestos por todo o mundo em várias capitais europeias (Diário de Notícias (2020). Berlim, Londres, Paris. Milhares nas ruas contra as medidas sanitárias anti-covid); em vários estados norte-americanos (SIC Notícias (2020). Covid-19: Manifestações contra restrições em vários estados dos EUA); no Brasil (CNN (2020). Grupo pró-Bolsonaro e anti-isolamento faz carreata e fecha avenida em São Paulo); na Austrália (TVI24 (2020). Covid-19: vários detidos em protestos contra medidas de confinamento na austrália); em África (Europapress (2020a). El Supremo de Malaui falla contra el confinamiento y ordena que sea aplazado siete días; Europapress (2020b). Níger detiene a más de cien personas y encarcela a diez por disturbios contra las restricciones; ABC (2020). Primeros disturbios en Kenia tras imponerse toque de queda por coronavirus; entre outros. 
ção civil e de emergência na prossecução das suas atribuições e competências. Desta forma, assumem-se como agentes de proteção civil primários que contribuem para a contenção pandémica, para a diminuição da propagação viral e, por conseguinte, para a retoma gradual da normalidade.

Contudo, importa assinalar que a par do progressivo desconfinamento e do regresso da normal atividade comercial, as polícias municipais e as equipas de policiamento de proximidade das forças de segurança devem adequar, adaptar e reestruturar as suas estratégias. Tendo em conta o reinício das atividades letivas, a abertura de grandes superfícies e do comércio local e a retoma da atividade de restauração e similares, é necessário reforçar a prossecução de campanhas de prevenção, sensibilização fiscalização, de modo a estimular um contínuo cumprimento das medidas impostas e a evitar um retrocesso no processo de desconfinamento.

A atual pandemia imprimiu a necessidade de reconfigurar as diretrizes securitárias, promovendo a cooperação e coordenação entre diversos serviços. A par das suas missões de segurança interna, as equipas de policiamento de proximidade das forças de segurança e as polícias municipais revelam-se agentes de proteção civil, contribuindo para a contenção pandémica e para o apoio aos cidadãos mais vulneráveis. Estes modelos de segurança surgem como concorrentes e parceiros securitários, apoiando a prevenção criminal, a missão de proteção civil e a missão de socorro na mais importante incumbência de reposição e manutenção da ordem e tranquilidade da sociedade.

Em situações de normalidade ou em situações de exceção, as estratégias de segurança comunitária assumem-se como uma mais-valia na prossecução da missão securitária. De facto, a materialização destas estratégias e a assunção da importância dos serviços de proteção civil, permitem-nos concluir que a segurança comunitária e a proteção civil integram o conceito de segurança nacional.

Data de receção: 18/09/2020

Data de aprovação: 12/11/2020

\section{Referências}

Obras gerais

Amaro, A. D. (2020). "Segurança comunitária e proteção civil”. In Associação Portuguesa de Riscos, Prevenção e Segurança (Ed.). Territorium: Revista Internacional de Riscos, n. ${ }^{\circ}$ 27. Coimbra: Associação Portuguesa de Riscos, Prevenção e Segurança.

Claro, R. (2018). “O Panorama Securitário Atual, Um Olhar Sobre a Península Ibérica”. In Correia, E. P. (Coord.). Políticas Públicas de Segurança, Lisboa, Instituto Superior de Ciências Policiais e Segurança Interna, pp. 14-58.

Correia, E. P. (2020). O Presidente da República em Democracia - Comandante Supremo das Forças Armadas, Lisboa: Edições Almedina, S.A.

Correia, E. P. (2018). Políticas Públicas de Segurança, Lisboa: Instituto Superior de Ciências Policiais e Segurança Interna. 
Gouveia, J. B. (2018). Direito da Segurança: Cidadania, soberania e cosmopolitismo. 1. ${ }^{\text {a }}$ edição. Coimbra: Edições Almedina, S.A.

Huntington, S. P. (1985). The Soldier and the State: The Theory and Politics of Civil-Military Relations, Cambridge, Belknap Press of Harvard University Press.

Pereira, R. (2017). "Políticas de Segurança: novos desafios e respostas”. In Gouveia, J. B. (Coord.). Revista de Direito e Segurança, n. ${ }^{\circ}$ 10. Lisboa: Instituto de Direito e Segurança.

Valente, M. G. (2013). Segurança - um tópico jurídico em reconstrução. Lisboa: Âncora Editora.

\section{Legislação}

Decreto de Aprovação da Constituição, aprova a Constituição da República Portuguesa. Diário da República, 1. a série, n. ${ }^{\circ} 86$ de 10 de abril de 1976.

Decreto do Presidente da República n. ${ }^{\circ}$ 14-A/2020, declara o estado de emergência, com fundamento na verificação de uma situação de calamidade pública. Diário da República, 1. a série, n. 55 de 18 de março.

Decreto do Presidente da República n. ${ }^{\circ}$ 17-A/2020, renova a declaração de estado de emergência, com fundamento na verificação de uma situação de calamidade pública. Diário da República, $1 .^{\text {a }}$ série, n. ${ }^{\circ} 66$ de 2 de abril.

Decreto do Presidente da República n. ${ }^{\circ}$ 20-A/2020, procede à segunda renovação da declaração de estado de emergência, com fundamento na verificação de uma situação de calamidade pública. Diário da República 1. ${ }^{\mathrm{a}}$ série, n. ${ }^{\circ} 76$ de 17 de abril.

Lei N. ${ }^{\circ}$ 50/2019, primeira alteração à Lei $n^{\circ}$ 19/2004, de 20 de maio, sobre a revisão da lei quadro que define o regime e forma de criação das polícias municipais, e primeira alteração ao Decreto-Lei $n .^{\circ}$ 239/2009, de 16 de setembro, que estabelece os direitos e os deveres dos agentes de polícia municipal. Diário da República, 1. a série, n.o 140 de 24 de julho.

Lei N..$^{8}$ o/2015, segunda alteração à Lei n. ${ }^{\circ} 27 / 2006$, de 3 de julho, que aprova a Lei de Bases da Proteção Civil. Diário da República, 1. a série, n. ${ }^{\circ} 149$ de 3 de agosto.

Lei N. ${ }^{\circ}$ 27/2006, aprova a Lei de Bases da Proteção Civil. Diário da República, 1. a série, n. 126 de 3 de julho.

Lei N. ${ }^{\circ}$ 19/2004, revisão da lei quadro que define o regime e forma de criação das polícias municipais. Diário da República, $1 .^{\text {a }}$ série, n. ${ }^{\circ} 118$ de 20 de maio.

\section{Imprensa}

ABC (2020). Primeros disturbios en Kenia tras imponerse toque de queda por coronavirus, de 28 de março. Consultado em 9 de setembro de 2020, através de <https://www.abc.es/ internacional/abci-primeros-disturbios-kenia-tras-imponerse-toque-queda-coronavirus-202003281106_video.html?ref=https\%3A\%2F\%2Fwww.google.com\%2F>.

CNN (2020). Grupo pró-Bolsonaro e anti-isolamento faz carreata e fecha avenida em São Paulo, de 18 de abril. Consultado em 8 de setembro de 2020, através de $<$ https://www. 
cnnbrasil.com.br/politica/2020/04/18/carreata-a-favor-de-bolsonaro-e-contra-doria-interdita-parte-da-avenida-paulista $>$.

Diário de Notícias (2020). Berlim, Londres, Paris. Milhares nas ruas contra as medidas sanitárias anti-covid, de 29 de agosto. Consultado em 10 de setembro de 2020, através de $<$ https://www.dn.pt/mundo/berlim-londres-paris-milhares-nas-ruas-contra-as-medidas-sanitarias-anti-covid-12564664.html>.

Europapress (2020a). El Supremo de Malauifalla contra el confinamiento yordena que sea aplazado siete días, de 24 de abril. Consultado em 6 de setembro de 2020, através de <https:// www.europapress.es/internacional/noticia-policia-malaui-usa-gases-lacrimogenosprotesta-comerciantes-contra-confinamiento-coronavirus-20200417151257.html>.

Europapress (2020b). Níger detiene a más de cien personas y encarcela a diez por disturbios contra las restricciones, de 21 de abril. Consultado em 10 de setembro de 2020, através de $<$ https://www.europapress.es/internacional/noticia-niger-detiene-mas-cien-personas-encarcela-diez-disturbios-contra-restricciones-coronavirus-20200421204137.html>.

SIC Notícias (2020). Covid-19: Manifestações contra restrições em vários estados dos EUA, de 18 de abril. Consultado em 5 de setembro de 2020, através de <https://sicnoticias.pt/ especiais/coronavirus/2020-04-18-Covid-19-Manifestacoes-contra-restricoes-emvarios-estados-dos-EUA>.

TVI24 (2020). Covid-19: vários detidos em protestos contra medidas de confinamento na austrália, de 5 de setembro. Consultado em 7 de setembro de 2020, através de <https:// tvi24.iol.pt/internacional/mascaras/covid-19-varios-detidos-em-protestos-contra-medidas-de-confinamento-na-australia>. 


\section{Sobre os autores}

eduardo pereira correia é doutor em Ciência Política e Relações Internacionais (Segurança e Defesa) pelo Instituto de Estudos Políticos da Universidade Católica Portuguesa, mestre em Direito e Segurança pela Faculdade de Direito da Universidade Nova de Lisboa e mestre em Ciência Política e Relações Internacionais pela Faculdade de Ciências Sociais e Humanas da Universidade Nova de Lisboa. Professor Auxiliar no Instituto Superior de Ciências Policiais e Segurança Interna (ISCPSI), Investigador Integrado do ICPOL-ISCPSI e Investigador no Observatório Político. [http://orcid.org/0000-0002-7113-0190]

RICARDo ClARo é doutorando em Direito e Segurança na NOVA School of Law da Universidade Nova de Lisboa, Mestre em Ciências Policiais pelo Instituto Superior de Ciências Policiais e Segurança Interna (ISCPSI), Oficial da Polícia de Segurança Pública e Investigador associado do Observatório Político. [https://orcid.org/0000-0002-2940-3183]

\footnotetext{
About the authors

eduardo pereira correia holds a PhD in Political Science and International Relations (Security and Defense) from the Institute for Political Studies at the Catholic University of Portugal, Master in Law and Security from the Nova School of Law and Master in Political Science and International Relations from the NOVA School of Social Sciences and Humanities. Assistant Professor at the Higher Institute of Police Sciences and Internal Security (ISCPSI), Integrated Researcher at ICPOL-ISCPSI and Researcher at the Political Observatory. [http://orcid.org/0000-0002-7113-0190]

RICARDo Claro is a PhD student in Law and Security at NOVA School of Law, Master in Police Sciences by the Higher Institute of Police Sciences and Internal Security (ISCPSI), Public Security Police Officer and Associate Researcher at the Political Observatory.

[https://orcid.org/0000-0002-2940-3183]
} 